\title{
Trust and performance in business teams: A meta-analysis
}

\author{
Amy M. Morrissette \\ Morrissette Consulting \\ Portland, Oregon, USA \\ Jennifer L. Kisamore \\ Department of Psychology and Organizational Dynamics \\ Schusterman Center \\ University of Oklahoma \\ Tulsa, Oklahoma, USA
}

Published in:

Morrissette, A.M., \& Kisamore, J.L. (2020). Trust and performance in business teams: A metaanalysis. Team Performance Management: An International Journal, 26(5/6), 287-300. https://doi.org/10.1108/TPM-02-2020-0012 


\begin{abstract}
Purpose - The aim of this study is two-fold. First, the nature of the relationship between team trust and team performance in the business context is determined. Second, both team design (team size and team type) and methodological moderators (source of criterion measure and study date) of the relationship are assessed.

Design/methodology/approach - A random-effects meta-analysis was performed on published and unpublished empirical studies. Subgroup moderator analyses were conducted using Cochran's $Q$. Continuous moderator analyses were conducted using meta-regression.

Findings - Data from 55 independent studies (3,671 teams) were pooled. Results indicated a large, positive relationship between team trust and team performance in real business teams. Further analyses indicated that the relationship was significantly moderated by business team type, team size, and source of criterion measure.
\end{abstract}

Research limitations/implications - Results indicate different team types, sizes, and performance criteria should not be treated as equivalent. Results are based on cross-sectional research and can only be generalized to business teams.

Practical implications - Managers should be attentive to trust issues in work teams as they may portend future performance problems or mirror other organizational issues that affect team performance. Team function and size predict how team trust is related to team performance.

Originality/value - The present study answers a call by Costa et al. (2018) for additional investigation of moderators of the trust-performance relationship in teams using a quantitative review of studies.

Keywords: team trust, team performance, meta-analysis, team size, team type, business teams, team function; criterion source 


\section{Trust and Performance in Business Teams: A Meta-Analysis \\ Introduction}

As organizations increasingly rely on teams, there has been a greater impetus to determine how team performance can be optimized. While traditional models of team functioning have focused on team processes (e.g., input-process-output model: McGrath, 1984), recent research (e.g., Carter et al., 2018; Shuffler et al., 2018) has shifted attention toward team emergent states - attitudes, values, and beliefs that arise out of team interactions and tend to vary with context (Marks et al. 2001). One emergent state that has intrigued both scholars and practitioners is team trust. Team trust has been conceptualized as "a shared psychological state among team members comprising willingness to accept vulnerability based on positive expectations of a specific other or others" (Fulmer and Gelfand, 2012: 1174).

In recent decades, a growing number of studies have examined the relationship between team trust and business team performance. Despite general optimism about the potential of team trust to enhance business team performance, results of empirical research have been highly inconsistent with correlations ranging from very weak to very strong. These inconsistencies may be a consequence of team design and methodological factors. In their meta-analyses, Breuer $e t$ al. (2016) and de Jong et al. (2016) found that various task (e.g., task interdependency) and process factors (e.g. virtuality) moderated the team trust-team performance relationship across different team contexts. Both meta-analyses aggregated data from studies conducted across an array of team contexts such as laboratory/simulated, business, academic, and athletic settings. Furthermore, the meta-analysis conducted by de Jong et al. (2016) treated teams, firms, districts, and schools as equivalent and regarded organization-wide performance measures and other types of outcomes, including innovativeness and satisfaction, as congruent to team performance. 
Breuer et al. (2016), however, found that effect sizes differed depending on the nature of the criteria correlated with team trust. Hence, this calls into question the practice of treating distinct outcomes as equivalent or generalizing across wide-ranging units and team contexts. As a result of these amalgamations, previous meta-analyses may have introduced extraneous heterogeneity. The current meta-analysis aims to advance understanding of the nature of the team trust-team performance relationship in business teams and identify moderators of the relationship.

This paper extends the work of Breuer et al. (2016) and de Jong et al. (2016) in several notable ways. First, it aims to summarize a significantly narrower stream of literature that examines the relationship between team trust and team performance in real business teams. Thus, results of the current study are applicable to and have implications for workplace teams and their managers. Likewise, directions for future research that build on the current study are clear given the relatively narrow inclusion criteria. Second, given that organizations increasingly rely on teams to achieve their objectives across different functional areas (Mathieu et al., 2014), this paper examines whether team size and team type moderate the trust-performance relationship in business teams. It is expected that the strength of the relationship will vary based on team size and type of business team (decision-making, project, production). In addition, the current study examines whether methodological moderators including source of criterion measure (internal, external, objective) and study date help to explain variance in effect sizes across primary studies. These four potential moderators have not been examined by previous meta-analyses on the topic. Furthermore, the current study answers Costa and colleagues' (2018) call for continued metaanalytic investigation of moderators of the trust-performance relationship in teams. 


\section{Team trust-team performance relationship}

According to Mayer and colleagues' (1995) organizational trust model, trust in an interdependent relationship leads to outcomes through risk-taking behavior. Specifically, a trusting party recognizes the benevolence, ability, and integrity of another party and subsequently is more likely to engage in a range of cooperative behaviors (e.g., delegating important tasks, supporting the process of change) with that party. These collective and compliant behaviors can help teams achieve their goals. Teams that are successful in developing trust among their members foster cooperation, which facilitates members' accomplishment of the shared team task.

Marketing and management scholars have shown considerable interest in the topic of team trust (e.g., Akgün et al., 2005; Dayan and Di Benedetto, 2010; Muethel at al., 2012) and asserted that high team output (e.g., decision, product) quality is often a function of trust between team members. For instance, Dayan and Di Benedetto (2010: 699) argued that team trust is a critical driver of new product performance; they pointed out "as team members develop trust, they develop new products with fewer technical problems, find and solve product problem areas with which customers are dissatisfied, and develop products better." As predicted, Dayan and Di Benedetto (2010) found that higher team trust was significantly related to higher new product success. More recent studies have also found large, positive correlations between team trust and team performance (e.g., Buvik and Tvedt, 2016; Chou et al., 2013; Lee et al., 2015). This suggests:

Hypothesis 1: Team trust will be positively associated with team performance in the business context and the effect size describing the relationship will be large. 


\section{Moderators of the team trust-team performance relationship}

This study also examines whether team design and methodological factors moderate the relationship between team trust and team performance. Team design moderators include team size and team type. Methodological moderators include source of criterion measure and study date.

Team size. Team size has been examined in other meta-analyses dealing with teams (e.g., LePine et al., 2008; Stahl et al., 2010). Process loss theory (Steiner, 1972) suggests that larger teams are subject to greater process losses (e.g., breakdowns in communication, coordination challenges) than smaller teams. Because processes give rise to emergent states (e.g., beliefs about the benevolence and integrity of another party), smaller teams may require less time to develop trust than larger teams. Smaller teams also tend to be more effective than larger teams (Mueller, 2012). Therefore, it is likely:

Hypothesis 2: Team size will significantly moderate the team trust-team performance relationship such that the relationship will be stronger for smaller as compared to larger teams.

Team type. Team type refers to the functional purpose of the team. According to D'Innocenzo et al. (2016: 1974), team type "is one of the more commonly examined moderators of team-related effect sizes in meta-analyses." Different types of teams have fundamentally different core tasks which may affect the nature of the interdependences needed for effective team performance. In their meta-analysis, DeChurch and Mesmer-Magnus (2010) argued that interdependencies in decision-making teams, which process information and make decisions or develop strategies, are largely informational in nature given their tasks require more cognitive than physical activities. Conversely, production teams which coordinate actions and perform 
physical tasks such as manufacturing a product, have more behavioral than informational interdependencies. They indicate that project teams are both informationally- and behaviorallyinterdependent and thus should fall between the other team types. This suggests, due to their informational interdependence, decision-making teams have greater relationship considerations given the critical role that building rapport and trust play in gaining buy-in and achieving consensus. Conversely, the greater behavioral demands of production teams may be characterized by higher levels of task-oriented than relationship-oriented exchanges which may hinder the development of strong social ties between team members. Thus, it follows:

Hypothesis 3: Team type will significantly moderate the team trust-team performance relationship such that the relationship will be strongest for decision-making teams and weakest for production teams.

Source of criterion measure. Team performance can be assessed by internal sources (team members themselves), external sources (non-team members), or objective sources (impartial measures such as sales profit). It is widely accepted that effect sizes are inflated when employees rate their own performance. Common source bias (see Podsakoff et al., 2003) may inflate the coefficient describing the team trust-team performance relationship when the source of criterion measure is internal. Conversely, objective sources of team performance generally do not lead to inflated performance scores. This suggests:

Hypothesis 4: Source of criterion measure will significantly moderate the team trust-team performance relationship such that the relationship will be strongest when an internal source is used and weakest when an objective source is used.

Study date. Another potential methodological moderator is study date. In the current meta-analysis, study date is used as a proxy for changes in social values, most notably an 
increasing focus on trust in matters concerning organizations. The magnitude of the effect size for the focal relationship is expected to be larger over the publication years of the primary studies for several reasons. Since the turn of the $21^{\text {st }}$ century, trust has become more salient in society due in part to several high-profile corporate scandals (e.g., Enron, Wells-Fargo) which spurred the passage of legislation, such as the Sarbanes-Oxley Act, to enhance trust and transparency in organizations (Hurley et al., 2013; Kramer and Lewicki, 2010). During this same period, the understanding of how to optimize trust and team performance has increased as a result of growing interest in both. For example, the number of research articles and books published on the topic of trust relevant to organizations has grown notably (see Figure 1). Thus, it is hypothesized:

Hypothesis 5: Study date will significantly moderate the team trust-team performance relationship such that the relationship will be stronger in more recent studies as compared to earlier studies.

Insert Figure 1 about here

\section{Method}

\section{Literature search}

Electronic searches of Business Source Premier, PsycINFO, Google Scholar, and Dissertation Abstracts databases, and major conferences (e.g., Academy of Management, Society for Industrial and Organizational Psychology, American Psychological Association) were conducted through January 2020. Several combinations of key terms were used including team trust, intrateam trust, collective trust, mutual trust, team performance, and/or team effectiveness. The reference sections of potentially relevant articles were also searched to locate 
studies that might be relevant. Unpublished studies (dissertations, theses, and professional works) were located for the same time period by searching ProQuest, Google Scholar, and the Social Science Research Network, as well as by contacting some prominent authors.

\section{Inclusion criteria}

Studies were eligible for inclusion if they reported a correlation coefficient for the relationship between trust and performance assessed at the team-level for business teams. Team performance was defined as the degree of task or goal achievement in terms of quality and/or quantity of output. In addition, only team performance measures were included; other criterion measures (e.g., team member satisfaction) were excluded from the current study. The inclusion criteria resulted in 56 studies; however, one of these studies (i.e., Potrafka, 2016) was identified as an outlier after inspecting the funnel plot. The corrected effect size for the study was near perfect in magnitude $(\rho=.96)$ and had a very narrow confidence interval $(.91$ to .98$)$. This outlier had an appreciable impact on heterogeneity - the $Q$ statistic increased by $21.3 \%$ (from 296.10 to 359.23). Also, though based on only 36 teams, inclusion of this one study would have increased the corrected mean effect size by $3.8 \%$ (from .479 to .497 ). Although including the study would lend further weight in support of Hypothesis 1, it was excluded given the aim of this study is to best represent the general team trust-team performance relationship and its heterogeneity. Removal of this outlier yielded a final sample of 55 studies as noted in the Reference section.

\section{Coding procedure}

The authors created a coding manual to outline the protocol for extracting data for sample size, effect size (correlation), moderator variables, and reliability estimates for both the criterion and predictor variables. Cronbach alpha coefficients were the preferred reliability coefficient although composite reliability coefficients were used when alpha values were not reported. 
Perfect reliability was assumed for objective team performance measures or when no criterion reliability was reported. Codes for team size were based on the average team size reported in studies; the median or the midpoint of a range of team sizes was used when the mean was not reported. Team type was coded as decision making (e.g., top management teams), production (e.g., manufacturing teams), or project (e.g., new product development teams) based on research on team type taxonomies (e.g., Devine et al., 1999; Sundstrom et al., 1990). Source of criterion measure was coded as internal (e.g., team member-rated team performance), external (e.g., customer-rated team performance), or objective (e.g., team income/profit). Study date was coded as the copyright date for published articles and book chapters; presentation year was used for unpublished works.

Both authors independently coded all the studies and then compared codes. Intercoder agreement was high (90.1\%). Coding discrepancies, which typically resulted from differences in values reported in text and tables, were resolved through discussion.

\section{Analyses}

Comprehensive Meta-Analysis version 3.3 was used to perform quantitative analyses (Biostat, 2014). Study effects sizes were corrected for measurement error based on procedures outlined by Schmidt and Hunter (2014). Data was synthesized based on a random-effects model per recommendations by Kisamore and Brannick (2008). A 95\% confidence interval was used to determine significance for the mean effect size. Heterogeneity was assessed utilizing the Cochran $Q$ statistic. Categorical moderators including team type and source of criterion measure were assessed using subgroup analyses. Continuous moderators including team size and study date were assessed with meta-regression. Publication bias was assessed using Duval and Tweedie's (2000) trim and fill procedure. 


\section{Results}

The 55 independent studies (3,671 teams) included: 43 journal articles, 7 doctoral dissertations, 3 master's theses, and 2 book chapters. Study dates ranged from 1996 to 2019. Sample sizes ranged from 15 teams to 162 teams $(M=66.7)$.

\section{Hypothesis 1}

Team trust was positively correlated with team performance $(\rho=.48 ; p<.001)$. The $95 \%$ confidence interval ranged from .42 to .54 ; the random-effects variance component was .07 . Based on work by Cohen (1992), the strength of the effect size was large given it was greater than .40 thus supporting Hypothesis 1. Therefore, higher levels of trust in business teams are generally associated with higher levels of team performance. Duval and Tweedie's (2000) trimand-fill analysis indicated no studies needed to be trimmed, thus the mean effect size ( $\rho=.48)$ did not need to be adjusted. These results imply that publication bias is unlikely.

The $Q$ statistic for heterogeneity was 293.04 and significant $(p<.001)$, suggesting that the team trust-team performance relationship is likely to be affected by other factors. This result supported proceeding with testing for the hypothesized moderators.

\section{Hypothesis 2}

Six studies did not report enough information about team size to allow for coding. Average team size for the remaining 49 studies ranged from 2.09 to 20.95 team members. The mean team size (20.95) in Dekker's (2008) study was determined to be an outlier as it was more than 3 standard deviations from the average of the team sizes coded. Thus, Dekker's (2008) study was eliminated for this moderator analysis only. Raw mean team size for the remaining 48 studies was 7.07; weighted mean team size was 6.76. As predicted in Hypothesis 2, the metaregression analysis yielded a coefficient of $-.031(\mathrm{Z}=-2.07, p=.039)$; the $95 \%$ confidence 
interval ranged from -.061 to -.002. Thus, team size significantly moderated the team trust-team performance relationship; the relationship was stronger in smaller teams.

Insert Table 1 about here

\section{Hypothesis 3}

As shown in Table 1, team type significantly moderated the relationship between team trust and team performance in business teams $(Q=8.26, p=.016)$. As predicted, the relationship was found to be strongest in decision-making teams $(\rho=.52)$ and weakest in production teams $(\rho=.25)$. The magnitude of relationship in project teams $(\rho=.51)$ fell between the magnitudes for the other two team types.

\section{Hypothesis 4}

Hypothesis 4 predicted source of criterion would moderate the team trust-team performance relationship. Results supported Hypothesis 4. Source of criterion measure significantly moderated the relationship between trust and performance in business teams, $(Q=$ 10.93, $p=.004)$. As shown in Table 1 , the relationship between team trust and team performance was strongest when team performance was measured internally $(\rho=.56)$, followed by use of external ratings $(\rho=.38)$; the relationship was weakest when objective performance measures were used $(\rho=.27)$.

\section{Hypothesis 5}

Hypothesis 5 indicated the relationship between trust and performance would be stronger for more recent studies due to societal changes in the salience of trust. Based on the 55 included studies, meta-regression results yielded a coefficient of 0.014 ; the $95 \%$ confidence interval ranged from -.001 to -.029. The magnitude of effect sizes tended to increase over time, but not 
significantly so. Hypothesis 5 was not supported; study date did not significantly moderate the team trust-team performance relationship $(\mathrm{Z}=1.83, p=.067)$.

\section{Discussion}

This study examined the association between team trust and team performance in real business teams and tested possible moderators of this relationship. The main team trust-team performance relationship was positive and large in magnitude. Thus, business team leaders should understand that the shared perception of trust within a team may foster higher levels of team performance. These findings also illustrate the importance of examining business contexts separately from other team contexts (e.g., academic, athletic) as the two previous meta-analyses found that the main relationship was lower in magnitude $(\rho=.27$ : Breuer et al., 2016; $\rho=.30$ : de Jong et al., 2016) than the current study, likely as a result of aggregating effect sizes from disparate team contexts.

Practitioners should also be mindful of team design factors such as team size and type that moderate the relationship between team trust and team performance. The results for team size revealed that the strength of the relationship tends to be significantly stronger as team size decreases. Work by Troth et al. (2012) focused on how outcomes of emergent states are particularly relevant in small teams in which team members have more intimate personal connections. Furthermore, process loss theory (Steiner, 1972) maintains that larger teams have greater process issues which can negatively affect the development of trust or be detrimental to performance; breakdowns in communication and coordination may hamper team efforts to foster these.

The results also indicate that the relationship between team trust and team performance differs across types of business team. The positive relationship between team trust and team 
performance was the strongest in decision making teams followed by project and production teams, respectively. This is likely because members in decision-making teams rely on information and ideas provided by other team members in order to commit to a strategy or decision. Production teams, however, create tangible objects and perform observable actions; they are less reliant on information exchange for performance. Thus, in some team types, quality of information and quantity of communication may be critical for team performance; these exchanges may also inherently foster trust.

Furthermore, the results for the methodological moderator of source of criterion measure indicate that when team performance measures are collected from internal sources, the relationship between trust and performance in those teams will generally be stronger than if either external ratings or objective sources are used. Thus, researchers are cautioned against treating data from different types of criterion sources as equivalent.

\section{Limitations and future directions}

There were several limitations in the present study. First, because cross-sectional data was used, the conclusions that could be drawn from this study are limited. Social exchange theory (Blau, 1964) suggests that trust evolves from shared experiences and is likely to grow stronger over time; therefore, it should be examined over time given its complexity (see Fry et al. 2017). Future research should examine the differences in the team trust-team performance relationship as a function of team tenure to determine whether there is a typical relationship trajectory as teams evolve over time. Meta-analytic work could then use different timepoints in the team's life to explore both whether team tenure moderates the team trust-team performance relationship and whether performance improvements follow rising levels of team trust. 
Second, the primary study coefficients used in this meta-analysis as well as the metaregression methods used for continuous moderator analyses assumed linear relationships. Future research both at the primary and secondary levels are encouraged to explore the possibility of curvilinear relationships between team trust and team performance. For example, higher levels of team trust may correspond to higher levels of performance up to a point and then the relationship flattens or weakens. Similarly, with the study date moderator designed to reflect changes in social values, the salience of specific values in society may wax and wane as is evident in Figure 1. Thus, curvilinear moderation models may be able to explain heretofore unexplained heterogeneity across studies.

Third, the current study was based on team trust referents that focused on trust within the team. Future studies should assess other referents, such as a team's trust in the organization or in the teams' leader.

Fourth, the moderators examined were limited to the variables available for coding. Other variables (e.g., team performance incentives, organizational support, team diversity) may affect the correlation between team trust and team performance.

\section{Conclusion}

Results of the current study support the idea that team trust is a key emergent state that is strongly associated with business team performance. This study is the first to investigate team size, team type, source of criterion measure, and study date as possible moderators of the relationship between trust and performance in business teams. As team leaders become more aware of the value of team trust on team outcomes, organizations will increasingly find ways to facilitate team trust and with it, task and goal achievement. 


\section{References}

(* indicates studies included in this meta-analysis)

*Aarts, J. J. (2013), "How can functional diversity and intragroup conflict influence team effectiveness and creativity in NPD teams?", master's thesis, Eindhoven University of Technology, Netherlands, 31 October.

*Akgün, A. E., Byrne, J., Keskin, H., Lynn, G. S. and Imamoglu, S. Z. (2005), "Knowledge networks in new product development projects: A transactive memory perspective", Information \& Management, Vol. 42 No. 8, pp. 1105-1120. doi:10.1016/j.im.2005.01.001

*Akgün, A. E., Keskin, H., Byrne, J. and Imamoglu, S. Z. (2007), “Antecedents and consequences of team potency in software development projects", Information \& Management, Vol. 44 No. 7, pp. 646-656. doi:10.1016/j.im.2007.08.001

*Akgün, A. E., Keskin, H., Lynn, G. and Dogan, D. (2012), "Antecedents and consequences of team sensemaking capability in product development projects", $R \& D$ Management, Vol. 42 No. 5, pp. 473-493. doi:10.1111/j.1467-9310.2012.00696.x

*Akgün, A. E., Lynn, G. S., Keskin, H. and Dogan, D. (2014), “Team learning in IT implementation projects: Antecedents and consequences", International Journal of Information Management", Vol. 34 No. 1, pp. 37-47. doi:10.1016/j.ijinfomgt.2013.09.007

*Antognoni, A. H. (2017), "Trust your company: A multimethod approach based on the Hero model", doctoral dissertation, Universitat Jaume, Spain, available at: http://www.tdx.cat/handle/10803/404719 (accessed 20 October 2019).

*Baruch, Y. and Lin, C. P. (2012), "All for one, one for all: Coopetition and virtual team performance", Technological Forecasting and Social Change, Vol. 79 No. 6, pp. 1155-1168. doi:10.1016/j.techfore.2012.01.008

Biostat (2014), Comprehensive meta-analysis v3.3 (software), Englewood, NJ, available at: http://meta-analysis.com.

*Blatt, R. (2008), "Developing relational capital in team-based new ventures", doctoral dissertation [3343011], University of Michigan, Ann Arbor, MI, available at: http://hdl.handle.net/2027.42/61690 (accessed 21 June 2016).

Blau, P. (1964), Exchange and Power in Social Life, John Wiley and Sons, New York, NY.

*Brahm, T. and Kunze, F. (2012), "The role of trust climate in virtual teams", Journal of Managerial Psychology, Vol. 27 No. 6, pp. 595-614. doi:10.1108/02683941211252446

Breuer, C., Hüffmeier, J. and Hertel, G. (2016), "Does trust matter more in virtual teams? A meta-analysis of trust and team effectiveness considering virtuality and documentation as moderators", Journal of Applied Psychology, Vol. 101 No. 8, pp. 1151-1177. doi:10.1037/ap10000113 
*Buvik, M. P. and Tvedt, S. D. (2016), "The impact of commitment and climate strength on the relationship between trust and performance in cross-functional project teams: A moderated mediation analysis", Team Performance Management: An International Journal, Vol. 22 No. 3/4, pp. 1-43. doi:10.1108/TPM-02-2015-0011

*Carmeli, A., Tishler, A. and Edmondson, A. C. (2012), “CEO relational leadership and strategic decision quality in top management teams: The role of team trust and learning from failure", Strategic Organization, Vol. 10 No. 1, pp. 31-54. doi:10.1177/1476127011434797

Carter, N., Carter, D. and DeChurch, L. (2018), "Implications of observability for the theory and measurement of emergent team phenomena", Journal of Management, Vol. 44 No. 4, pp. 13981425. doi:10.1177/0149206315609402

*Chang, J. W., Sy, T. and Choi, J. N. (2012), "Team emotional intelligence and performance: Interactive dynamics between leaders and members", Small Group Research, Vol. 43 No. 1, pp. 75-104. doi:10.1177/1046496411415692

*Chou, H. W., Lin, Y. H., Chang, H. H. and Chuang, W. W. (2013), "Transformational leadership and team performance" SAGE Open, Vol. 3 No. 3, pp. 1-10. doi: $10.1177 / 2158244013497027$

*Chuang, W. W., Chou, H. W. and Yeh, Y. J. (2004), "The impacts of trust, leadership and collective efficacy on cross-functional team performance", paper presented at Proceedings from the Second Workshop on Knowledge Economy and Electronic Commerce, Taiwan, pp. 1-12.

Cohen, J. (1992), “A power primer”, Psychological Bulletin, Vol. 112 No. 1, pp. 155-159. doi:10.1037/0033-2909.112.1.155.

*Cohen, S. G., Ledford, G. E. and Spreitzer, G. M. (1996), “A predictive model of self-managing work team effectiveness", Human Relations, Vol. 49 No. 5, pp. 643-676.

doi:10.1177/001872679604900506

Costa, A. C., Fulmer, C. A. and Anderson, N. R. (2018), "Trust in work teams: An integrative review, multilevel model, and future directions", Journal of Organizational Behavior, Vol. 39 No. 2, pp. 169-184. doi:10.1002/job.2213

*Costa, A. C., Roe, R. A. and Taillieu, T. (2001), “Trust within teams: The relation with performance effectiveness", European Journal of Work and Organizational Psychology, Vol. 10 No. 3, pp. 225-244. doi:10.1080/13594320143000654

D’Innocenzo, L., Mathieu, J. E. and Kukenberger, M. R. (2016), “A meta-analysis of different forms of shared leadership-team performance relations", Journal of Management, Vol. 42 No. 7, pp. 1964-1991. doi:10.1177/0149206314525205

*Dayan, M. and Di Benedetto, C. A. (2010), "The impact of structural and contextual factors on trust formation in product development teams", Industrial Marketing Management, Vol. 39 No. 4, pp. 691-703. doi:10.1016/j.indmarman.2010.01.001 
DeChurch, L. A. and Mesmer-Magnus, J. R. (2010), "The cognitive underpinnings of effective teamwork: A meta-analysis", Journal of Applied Psychology, Vol. 95 No. 1, pp. 32-53. doi:10.1037/a0017328

*De Jong, B. A., Bijlsma-Frankema, K. M. and Cardinal, L. B. (2014), "Stronger than the sum of its parts? The performance implications of peer control combinations in teams", Organization Science, Vol. 25 No. 6, pp. 1703-1721. doi:10.1287/orsc.2014.0926

*De Jong, B. A. and Dirks, K. T. (2012), "Beyond shared perceptions of trust and monitoring in teams: Implications of asymmetry and dissensus", Journal of Applied Psychology, Vol. 97 No. 2, pp. 391-406. doi:10.1037/a0026483

De Jong, B. A., Dirks, K. T. and Gillespie, N. (2016), “Trust and team performance: A metaanalysis of main effects, moderators and covariates", Journal of Applied Psychology, Vol. 101 No. 8, pp. 1134-1150. doi:10.1037/ap10000110

*De Jong, B. A. and Elfring, T. (2010), "How does trust affect the performance of ongoing teams? The mediating role of reflexivity, monitoring and effort", Academy of Management Journal, Vol. 53 No. 3, pp. 535-549. doi:10.5465/AMJ.2010.51468649

*Dekker, D. M. (2008), “Global virtual teams: Enhancing effectiveness”, doctoral dissertation, Eindhoven University of Technology, Netherlands, available at:

http://dx.doi.org/10.6100/IR637974 (accessed 28 June 2016).

Devine, D. J., Clayton, L. D., Philips, J. L., Dunford, B. B. and Melner, S. B. (1999), “Teams in organizations prevalence, characteristics, and effectiveness", Small Group Research, Vol. 30 No. 6, pp. 678-711. doi:10.1177/104649649903000602

*Donati, S. (2013), “An input-process-output approach to interorganizational teams: The influence of work group diversity, trust and shared leadership on communication network and team output", doctoral dissertation, Bologna University, Italy, available at:

http://amsdottorato.unibo.it/5853/1/Simone_Donati_2013_PhD_Dissertation.pdf (accessed 10 April 2016).

*Druskat, V.U. and Pescosolido, A.T. (2006), "The impact of emergent leader emotionally competent behavior on team trust, communication, engagement, and effectiveness", in Zerbe, W.J., Ashkanasy, N. and Hartel C. (Eds.), Research on Emotions in Organizations: Individual and Organizational Perspectives on Emotion Management and Display, Emerald, Bingley, UK, pp. 25-55.

Duval, S. and Tweedie, R. (2000), "Trim and fill: A simple funnel-plot-based method of testing and adjusting for publication bias in meta-analysis", Biometrics, Vol. 56 No. 2, pp. 455-463.

Fry, T. N., Nyein, K. P. and Wildman, J. L. (2017), "Team trust development and maintenance over time", in Salas, E., Vessey, W.B. and Landon, L.B. (Eds.), Research on Managing Groups and Teams: Team Dynamics Over Time, Emerald, Bingley, UK, pp. 123-153. 
Fulmer, C. A. and Gelfand, M. J. (2012), “At what level (and in whom) we trust: Trust across multiple organizational levels", Journal of Management, Vol. 38 No. 4, pp. 1167-1230. doi:10.1177/0149206312439327

*Gupta, N., Ho, V., Pollack, J. M. and Lai, L. (2016), “A multilevel perspective of interpersonal trust: Individual, dyadic and cross-level predictors of performance", Journal of Organizational Behavior, Vol. 37 No. 8, pp. 1271-1292. doi:10.1002/job.2104

*Hakonen, M. and Lipponen, J. (2009). "It takes two to tango: The close interplay between trust and identification in predicting virtual team effectiveness", Journal of eWorking, Vol. 3 No. 1, pp. 17-32.

*Harvey, D. L. (2010), “A team process and emergent states approach to understanding team conflict and outcomes", doctoral dissertation [3436073], Pennsylvania University.

*Hempel, P. S., Zhang, Z. X. and Tjosvold, D. (2009), "Conflict management between and within teams for trusting relationships and performance in China", Journal of Organizational Behavior, Vol. 30 No. 1, pp. 41-65. doi:10.1002/job.540

*Hertel, G., Konradt, U. and Orlikowski, B. (2004), "Managing distance by interdependence: Goal setting, task interdependence and team-based rewards in virtual teams", European Journal of Work and Organizational Psychology, Vol. 13 No. 1, pp. 1-28.

doi:10.1080/13594320344000228

*Hu, J. (2012), “A team-level social exchange model: The antecedents and consequences of leader-team exchange", doctoral dissertation [3550906], University of Illinois at Chicago.

*Huang, C. C. (2009), "Knowledge sharing and group cohesiveness on performance: An empirical study of technology R\&D teams in Taiwan”, Technovation, Vol. 29 No. 11, pp. 786797. doi:10.1016/j.technovation.2009.04.003

*Hughes, M., Rigtering, J. C., Covin, J. G., Bouncken, R. B. and Kraus, S. (2018), "Innovative behaviour, trust and perceived workplace performance", British Journal of Management, Vol. 29 No. 4, pp. 750-768. doi:10.1111/1467-8551.12305

Hurley, R. F., Gillespie, N., Ferrin, D. L. and Dietz, G. (2013), “Designing trustworthy organizations", MIT Sloan Management Review, Vol. 54 No. 4, pp. 75-82.

*Joshi, A., Lazarova, M. B. and Liao, H. (2009), "Getting everyone on board: The role of inspirational leadership in geographically dispersed teams", Organization Science, Vol. 20 No. 1, pp. 240-252. doi:10.1287/Orsc.1080.0383

*Khan, M. S., Breitenecker, R. J., Gustafsson, V. and Schwarz, E. J. (2015), “Innovative entrepreneurial teams: The give and take of trust and conflict", Creativity and Innovation Management, Vol. 24 No. 4, pp. 558-573. doi:10.1111/caim.12152 
*Khan, M. S., Breitenecker, R. and Schwarz, E. J. (2014), "Entrepreneurial team locus of control: Diversity and trust", Management Decision, Vol. 52 No. 6, pp. 1057-1081.

doi:10.1108/MD-06-2013-0349

Kisamore, J. L. and Brannick, M. T. (2008), “An illustration of the consequences of metaanalysis model choice”, Organizational Research Methods, Vol. 11 No. 1, pp. 35-53. doi:10.1177/1094428106287393

Kramer, R. M. and Lewicki, R. J. (2010). "Repairing and enhancing trust: Approaches to reducing organizational trust deficits", Academy of Management Annals, Vol. 4 No. 1, pp. 245277. doi:10.1080/19416520.2010.487403

*Lee, P., Gillespie, N., Mann, L. and Wearing, A. (2010), "Leadership and trust: Their effect on knowledge sharing and team performance", Management Learning, Vol. 41 No. 4, pp. 473-491. doi:10.1177/1350507610362036

*Lee, J., Park, J. G. and Lee, S. (2015), "Raising team social capital with knowledge and communication in information systems development projects", International Journal of Project Management, Vol. 33 No. 4, pp. 797-807. doi:10.1016/j.ijproman.2014.12.001

*Lee, D., Stajkovic, A. D. and Sergent, K. (2016), "A field examination of the moderating role of group trust in group efficacy formation", Journal of Occupational and Organizational Psychology, Vol. 89 No. 4, pp. 856-876. doi:10.1111/joop.12161

LePine, J. A., Piccolo, R. F., Jackson, C. L., Mathieu, J. E. and Saul, J. R. (2008), “A metaanalysis of teamwork processes: Tests of a multidimensional model and relationships with team effectiveness criteria”, Personnel Psychology, Vol. 61 No. 2, pp. 273-307. doi:10.1111/j.17446570.2008.00114.x

*Lvina, E. (2011), "Political skill in the team context: Team political skills composition and team effectiveness", doctoral dissertation, Concordia University, available at: http://spectrum.library.concordia.ca/7800/1/Lvina_PhD_F2011.pdf (accessed 21 April 2016).

*Lyubovnikova, J., Legood, A., Turner, N. and Mamakouka, A. (2015), "How authentic leadership influences team performance: The mediating role of team reflexivity", Journal of Business Ethics, Vol. 141 No. 1, pp. 59-70. doi:10.1007/s10551-015-2692-3

Marks, M.A., Mathieu, J.E. and Zaccaro, S.J. (2001). "A temporally based framework and taxonomy of team processes”, Academy of Management Review, Vol. 26 No. 3, pp. 356-376.

*Martínez-Tur, V., Gracia, E., Moliner, C., Molina, A., Kuster, I., Vila, N. and Ramos, J. (2016), "The moderating role of performance in the link from interactional justice climate to mutual trust between managers and team members", Psychological Reports, Vol. 118 No. 3, pp. 870-888. doi:10.1177/0033294116647689

Mathieu, J. E., Tannenbaum, S. I., Donsbach, J. S. and Alliger, G. M. (2014), “A review and integration of team composition models moving toward a dynamic and temporal framework", Journal of Management, Vol. 40 No. 1, pp. 130-160. doi:10.1177/0149206313503014 
Mayer, R. C., Davis, J. H. and Schoorman, F. D. (1995), “An integrative model of organizational trust”, Academy of Management Review, Vol. 20 No. 3, pp. 709-734.

doi:10.5465/AMR.1995.9508080335

McGrath. J. E. (1984), “Group Interaction and Performance”, Prentice-Hall, Englewood Cliffs, NJ.

*Meurs, T. P. M. (2015), "Determining the success factors of Scrum projects”, master's thesis, Eindhoven University of Technology, Netherlands, available at:

http://pure.tue.nl/ws/files/47029074/798460-1.pdf (accessed 26 February 2016).

Mueller, J. S. (2012). "Why individuals in larger teams perform worse", Organizational Behavior and Human Decision Processes, Vol. 117 No. 1, pp. 111-124.

doi:10.1016/j.obhdp.2011.08.004

*Muethel, M., Siebdrat, F. and Hoegl, M. (2012), "When do we really need interpersonal trust in globally dispersed new product development teams?”, R\&D Management, Vol. 42 No. 1, pp. 3146. doi:10.1111/j.1467-9310.2011.00667.x

*Olson, B. J., Parayitam, S. and Bao, Y. (2007), "Strategic decision making: The effects of cognitive diversity, conflict and trust on decision outcomes", Journal of Management, Vol. 33

No. 2, pp. 196-222. doi:10.1177/0149206306298657

*Olvera-Calderón, J., Llorens-Gumbau, S., Acosta-Antognoni, H. and Salanova-Soria, M. (2017), "Transformational leadership and horizontal trust as antecedents of team performance in the healthcare context", Annals of Psychology, Vol. 33 No. 2, pp. 365-375.

doi:10.6018/analesps.33.2.237291

*Parayitam, S. and Dooley, R. S. (2007), "The relationship between conflict and decision outcomes: Moderating effects of cognitive- and affect-based trust in strategic decision-making teams", International Journal of Conflict Management, Vol. 18 No. 1, pp. 42-73.

doi:10.1108/10444060710759318

*Pinjani, P. and Palvia, P. (2013), "Trust and knowledge sharing in diverse global virtual teams", Information \& Management, Vol. 50 No. 4, pp. 144-153. doi:10.1016/j.im.2012.10.002

Podsakoff, P. M., MacKenzie, S. B., Lee, J. Y. and Podsakoff, N. P. (2003), “Common method biases in behavioral research: A critical review of the literature and recommended remedies", Journal of Applied Psychology, Vol. 88 No. 5, pp. 879-903.

*Politis, J. D. (2003), "The connection between trust and knowledge management: What are its implications for team performance", Journal of Knowledge Management, Vol. 7 No. 5, pp. 5566. doi:10.1108/13673270310505386

Potrafka, K. (2016), “The relationship between team mental models, interpersonal trust and team performance in knowledge-based teams", doctoral dissertation [10007220], Fielding Graduate University. 
*Rezvani, A., Barrett, R. and Khosravi, P. (2019), "Investigating the relationships among team emotional intelligence, trust, conflict and team performance", Team Performance Management: An International Journal, Vol. 25 No. 1/2, pp. 120-137. doi:10.1108/TPM-03-2018-0019

*Rispens, S., Greer, L. L. and Jehn, K. A. (2007), "It could be worse: A study on the alleviating roles of trust and connectedness in intragroup conflicts", International Journal of Conflict Management, Vol. 18 No. 4, pp. 325-344. doi:10.1108/10444060710833450

*Scheuer, C. L. and Loughlin, C. (2019), "The moderating effects of status and trust on the performance of age-diverse work groups", Evidence-based HRM: A global forum for empirical scholarship, Vol. 7 No. 1, pp. 56-74. doi:10.1108/EBHRM-01-2018-0008.

Schmidt, F. L. and Hunter, J. E. (2014), Methods of Meta-analysis: Correcting Error and Bias in Research Findings ( $3^{r d}$ ed.), Sage, Thousand Oaks, CA.

Shuffler, M., Kramer, W., Carter, D., Thayer, A. and Rosen, M. (2018), "Leveraging a teamcentric approach to diagnosing multiteam system functioning: The role of intrateam state profiles", Human Resource Management Review, Vol. 28 No. 4, pp. 361-361.

doi:10.1016/j.hrmr.2017.08.003

*Spreitzer, G. M., Noble, D. S., Mishra, A. K. and Cooke, W. N. (1999), "Predicting process improvement team performance in an automotive firm: Explicating the roles of trust and empowerment", in Wageman, R. (Ed.), Research on Managing Groups and Teams: Groups in Context, Elsevier, Stamford, CT, pp. 71-92.

Stahl, G. K., Maznevski, M. L., Voigt, A. and Jonsen, K. (2010), "Unraveling the effects of cultural diversity in teams: A meta-analysis of research on multicultural work groups", Journal of International Business Studies, Vol. 41 No. 4, pp. 690-709.

Steiner, I. D. (1972), Group Processes and Group Productivity, Academic, New York, NY.

*Stewart, K. J. and Gosain, S. (2006), "The impact of ideology on effectiveness in open source software development teams”, MIS Quarterly, Vol. 30 No. 2, pp. 291-314.

doi: $10.2307 / 25148732$

Sundstrom, E., De Meuse, K. P. and Futrell, D. (1990), "Work teams: Applications and effectiveness", American Psychologist, Vol. 45 No. 2, pp. 120-133.

Troth, A. C., Jordan, P. J., Lawrence, S. A. and Tse, H. H. (2012), “A multilevel model of emotional skills, communication performance, and task performance in teams", Journal of Organizational Behavior, Vol. 33 No. 5, pp. 700-722. doi:10.1002/job.785

*Webber, S. S. (2008), “Blending service provider-client project teams to achieve client trust: Implications for project team trust, cohesion, and performance", Project Management Journal, Vol. 39 No. 2, pp. 72-81. doi:10.1002/pmj.20043

*Weimar, E. (2013), “The influence of teamwork quality on software development team performance", master's thesis, Tilberg University, Netherlands. 
*Wiedow, A., Konradt, U., Ellwart, T. and Steenfatt, C. (2013), "Direct and indirect effects of team learning on team outcomes: A multiple mediator analysis", Group Dynamics: Theory, Research and Practice, Vol. 17 No. 4, pp. 232-251. doi:10.1037/a0034149 


\section{Table 1.}

Summary of Categorical Moderator Analyses

\begin{tabular}{|c|c|c|c|c|c|}
\hline Moderator variables & $k$ & $\rho$ & $95 \% \mathrm{CI}$ & $Q$-value & $\tau^{2}$ \\
\hline \multicolumn{6}{|l|}{ Team type } \\
\hline Decision-making & 9 & $0.518^{* * *}$ & $0.405-0.615$ & & 0.011 \\
\hline Project & 19 & $0.512 * * *$ & $0.430-0.585$ & & 0.054 \\
\hline Production & 6 & $0.252 * *$ & $0.064-0.423$ & & 0.000 \\
\hline Test for level difference & 34 & $0.446^{* * *}$ & $0.292-0.578$ & $8.258^{*}$ & 0.043 \\
\hline \multicolumn{6}{|l|}{ Source of criterion measure } \\
\hline Internal & 25 & $0.558 * * *$ & $0.475-0.631$ & & 0.109 \\
\hline External & 19 & $0.377 * * *$ & $0.257-0.485$ & & 0.017 \\
\hline Objective & 6 & $0.265^{*}$ & $0.033-0.470$ & & 0.000 \\
\hline Test for level difference & 50 & $0.421 * * *$ & $0.230-0.581$ & $10.932 * *$ & 0.070 \\
\hline
\end{tabular}

Note. $k=$ number of studies; $\rho=$ mean corrected correlation coefficient; $\mathrm{CI}=$ confidence interval; $Q=$ test of heterogeneity among levels; $\tau^{2}=$ random-effects variance component. ${ }^{*} p<0.05 ; * * p<0.01 ; * * *<0.001$ 


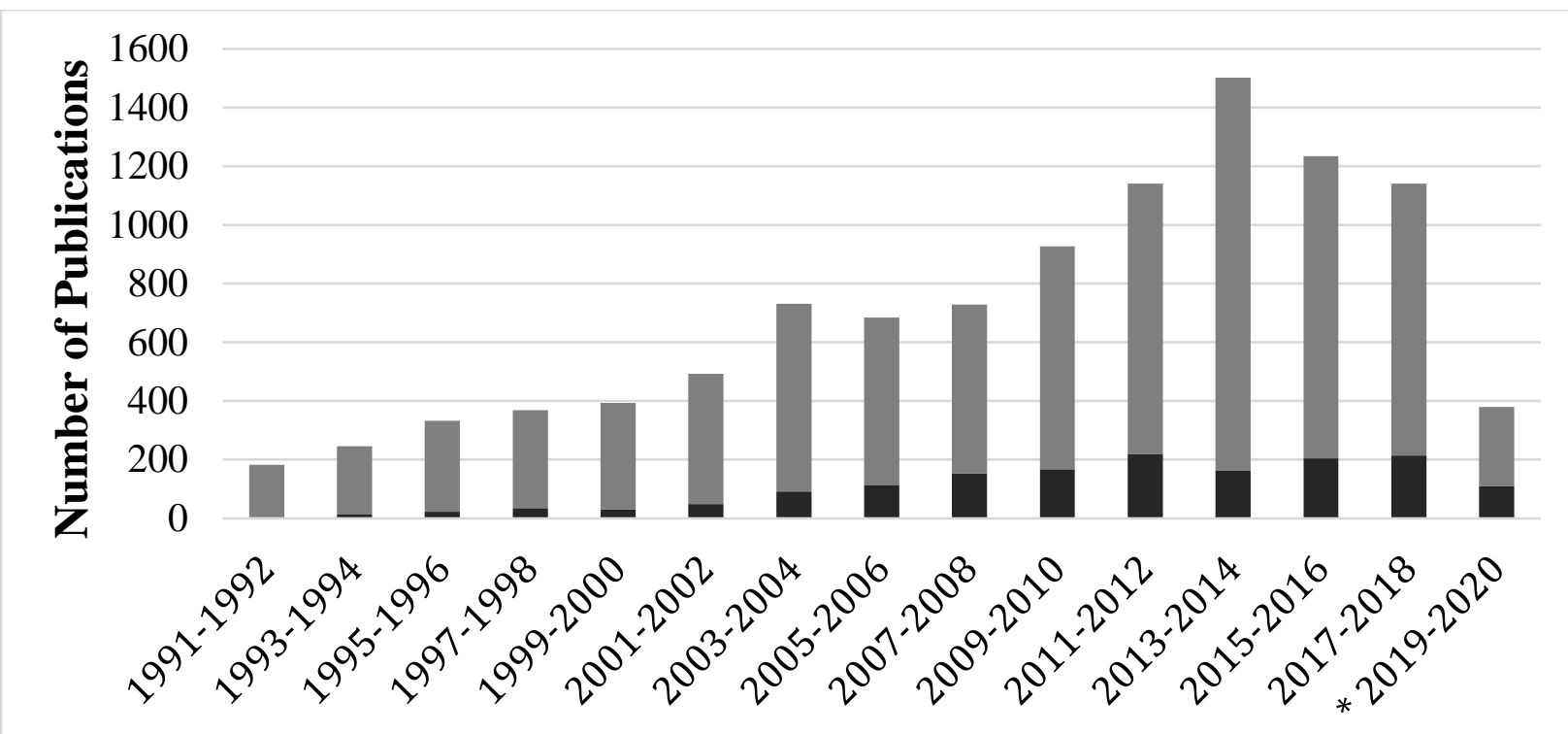

Publication Years

- Scholarly Articles $\quad$ Books

Figure 1. A graphical representation of scholar and mainstream interest in trust. Darker segments of the bars represent articles on "trust" indexed in PsycINFO. Data were retrieved through a titlebased search using the term "trust" along with six classifications including social psychology, group and interpersonal processes, organizational behavior, cognitive processes, industrial and organizational psychology, and general psychology. Search results were further limited to peerreviewed articles. Lighter segments of the bars represent books published on "trust," "team trust," and "group trust" in Dewey decimal system call numbers from 302 to 305 in the Books in Print database. Data were retrieved through a subject keyword search.

Note: * represents an incomplete record given the search was completed in April 2020. 